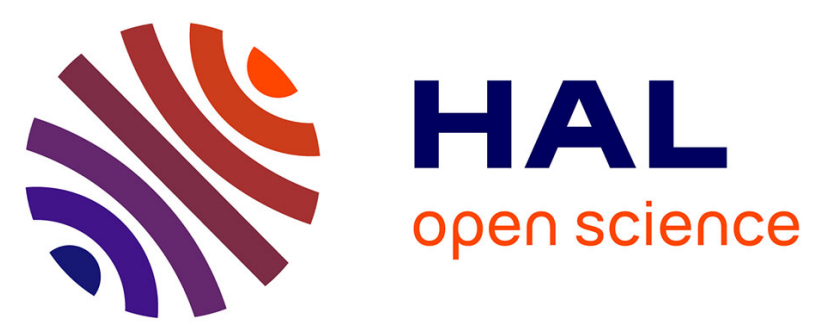

\title{
Fullerene-grafted block copolymers used as compatibilizer in P3HT/PCBM bulk heterojunctions: morphology and photovoltaic performances
}

Véronique Gernigon, Patrick Lévêque, Cyril Brochon, Jean-Nicolas Audinot, Nicolas Leclerc, Rony Bechara, Fanny Richard, Thomas Heiser, Georges Hadziioannou

\section{To cite this version:}

Véronique Gernigon, Patrick Lévêque, Cyril Brochon, Jean-Nicolas Audinot, Nicolas Leclerc, et al.. Fullerene-grafted block copolymers used as compatibilizer in P3HT/PCBM bulk heterojunctions: morphology and photovoltaic performances. European Physical Journal: Applied Physics, 2011, 56 (3), pp.34107. 10.1051/epjap/2011110150 . hal-00756413

\section{HAL Id: hal-00756413 https://hal.science/hal-00756413}

Submitted on 23 Nov 2012

HAL is a multi-disciplinary open access archive for the deposit and dissemination of scientific research documents, whether they are published or not. The documents may come from teaching and research institutions in France or abroad, or from public or private research centers.
L'archive ouverte pluridisciplinaire HAL, est destinée au dépôt et à la diffusion de documents scientifiques de niveau recherche, publiés ou non, émanant des établissements d'enseignement et de recherche français ou étrangers, des laboratoires publics ou privés. 


\title{
Fullerene-grafted block copolymers used as compatibilizer in P3HT/PCBM bulk heterojunctions: morphology and photovoltaic performances
}

Véronique Gernigon ${ }^{1}$, Patrick Lévêque ${ }^{1}$, Cyril Brochon ${ }^{2}$, Jean-Nicolas Audinot ${ }^{3}$, Nicolas Leclerc $^{4}$, Rony Bechara ${ }^{1}$, Fanny Richard ${ }^{4}$, Thomas Heiser ${ }^{1}$ and Georges Hadziioannou ${ }^{2 *}$

${ }^{1}$ Institut d'Électronique du Solide et des Systèmes (InESS), Université de Strasbourg, CNRS, 23 rue du Loess, 67037 Strasbourg, France

E-mail : thomas.heiser@unistra.fr

${ }^{2}$ Laboratoire de Chimie des Polymères Organiques, Ecole Nationale Supérieure de Chimie, de Biologie \& de Physique, Université Bordeaux 1, 16 Avenue Pey-Berland, 33607 Pessac, France

E-mail : hadzii@enscbp.fr

${ }^{3}$ Department Science and Analysis of Materials, Public Research Centre Gabriel Lippmann, 41 rue du Brill, L-4422 Belvaux, Luxembourg

${ }^{4}$ Laboratoire d'Ingénierie des Polymères pour les Hautes Technologies (LIPHT), Ecole Européenne de Chimie des Polymères et Matériaux (ECPM), 25 rue Becquerel, 67087 Strasbourg, France

\section{$\mathrm{C}_{60}$-grafted block copolymers used as compatibilizer in P3HT/PCBM blends}

\begin{abstract}
The nanostructure of the active layer in polymer/fullerene bulk heterojunction solar cells is known to have a strong impact on the device performances. Controlling the polymer/fullerene blend morphology is therefore particularly important. In this work, a rod-coil block copolymer, based on a regio-regular poly(3-hexylthiophene) electron-donor rod block and a $\mathrm{C}_{60}$-grafted coil block, is used as compatibilizer and its influences on the thin film morphology as well as the photovoltaic performances are investigated. It is shown that a small fraction of compatibilizer can enhance the device performances in an otherwise nonoptimized process. At higher fractions or long annealing times however, the fullerene-grafted copolymer is found to behave as a nucleation center and triggers the formation of fullerene crystals.
\end{abstract}

\section{Introduction}

The active layer of polymer/fullerene bulk heterojunction (BHJ) solar cells consists of an interpenetrating network formed by the electron-donor (D) $\pi$-conjugated polymer and the electron-acceptor (A) fullerene derivative. The currently most investigated devices use blends of regioregular poly(3-hexylthiophene) (rr-P3HT) and [6,6]-phenyl-C61-butyric acid methyl ester (PCBM) and have reached power conversion efficiencies (PCE) up to 5\% [1]. In these devices, the active layer nanostructure determines to a great extend the overall device performances [2-6]. Ideally, the donor and acceptor materials should form nanoscale interpenetrating networks to ensure an efficient exciton dissociation and charge transport. It is 
thus of considerable importance to control the blend morphology and in particular to avoid macro-phase separation during film deposition as well as during long term device operation. Previous attempts to control the blend morphology include exposure to solvent vapour, thermal annealing, as well as the inclusion of additives (such as selective solvents) during the film formation procedure [7-10]. The use of D/A block-copolymers[11-15] as compatibilizer in polymer/fullerene blends offers another particularly attractive strategy to control the morphology. Sivula et al. first succeeded to avoid thermal phase segregation by introducing small amounts of a diblock copolymer into the P3HT/PCBM blend [13]. Their polymer blocks incorporated a P3HT macromonomer and a grafted fullerene monomer, respectively, giving rise to a selective affinity of both blocks with the corresponding blend components. More recently, Lee et al. used a fullerene end-capped P3HT as compatibilizer in P3HT/PCBM blends and were able to suppress phase segregation after prolonged annealing [14]. Furthermore, Kim et al. explored the influence of the thiophene block length of a thiophene$\mathrm{C}_{60}$ dyad that was used as compatibilizer in P3HT/PCBM blends. Their results highlight the strong dependence of the compatibilizer molecular structure on its effectiveness to stabilize the blend morphology [15]. In the present study we use as compatibilizer a rod-coil block copolymer based on a regio-regular P3HT rod-block and a poly(butylacrylate-stat- $\mathrm{C}_{60^{-}}$ methylstyrene) $\left[\mathrm{P}\left(\mathrm{BA}-\right.\right.$ stat $\left.^{\left.-\mathrm{C}_{60} \mathrm{MS}\right)}\right]$ coil-block. Both, the common chemical nature of the rod block with the electron-donor polymer (P3HT) and the expected strong affinity between the grafted fullerene and PCBM, make this copolymer a good candidate for this application. We have investigated the impact of the compatibilizer on the photovoltaic (PV) device performances as a function of annealing time and of the amount of compatibilizer. Also, the thin film morphology was studied by using atomic force microscopy (AFM) and spatially resolved secondary ion mass spectrometry (SIMS) in order to correlate the behavior of the PV devices to modifications in the thin film morphology.

\section{Experimental section}

\subsection{Materials}

The structure of the P3HT- $b-\mathrm{P}\left(\mathrm{BA}-\right.$ stat- $\left._{60} \mathrm{MS}\right)$ copolymer used as compatibilizer is shown in Scheme 1. The rod-coil block copolymer has been obtained by a "living"/control radical polymerization of a PBA-co-CMS statistical block from a P3HT macro-initiator. The latter has been obtained by the Grignard metathesis (GRIM) polymerization method, as described by McCullough et al. [16]. The final block copolymer was obtained by grafting fullerenes onto the CMS moieties via an azidation step. More details on the synthesis procedure can be found in reference [17]. The rod and coil block characteristics are summarized in Table 1.

The P3HT and PCBM were commercial products and were used as received. The P3HT was purchased at two different suppliers (Aldrich and Merck). Regio-regularity and molecular weight, measured respectively by $1 \mathrm{H}$ NMR and by GPC, were $90 \%$ of regioregularity and $24.3 \mathrm{~kg} \cdot \mathrm{mol}^{-1}$ for the Aldrich batch and $97 \%$ of regioregularity and $20 \mathrm{~kg}$. $\mathrm{mol}^{-1}$ for the Merck batch.

The Aldrich material was used for the investigation of the device thermal stability, while the Merck polymer was used for all other experiments.

\subsection{Thin film deposition and characterization}

For AFM investigations, thin films of P3HT /PCBM/Compatibilizer ternary blends were spincoated from a diluted ortho-dichlorobenzene solution onto freshly cleaved mica substrates. The PCBM weight fraction was fixed to 0.5 , while the P3HT and compatibilizer fractions were set to $0.5-\mathrm{x}$ and $\mathrm{x}$, respectively, where $\mathrm{x}$ was varied between 0 and 0.1 . Thermal annealing of the samples has been done under nitrogen atmosphere. 
The film surface morphology was investigated by atomic force microscopy using a VEECO Multimode microscope in tapping mode. Additionally, ternary and binary organic layers have been imaged with the NanoSIMS50 set-up from CAMECA [18]. A Cs (1 pA) primary beam (with impact energy of $16 \mathrm{keV}$ ) was rastered over a $20 \mu \mathrm{m} * 20 \mu \mathrm{m}$ area on the sample surface with a spatial resolution of $50 \mathrm{~nm}$ (spot size). The two-dimensional images were recorded with $256 * 256$ pixels, using an acquisition time of $5 \mathrm{~ms}$ per pixel and a parallel detection of four different negative secondary ions $\left({ }^{12} \mathrm{C},{ }^{12} \mathrm{C}{ }^{1} \mathrm{H},{ }^{16} \mathrm{O}\right.$ and $\left.{ }^{32} \mathrm{~S}\right)$.

\subsection{Photovoltaic device elaboration and characterization}

Bulk heterojunction devices were elaborated using P3HT as electron donor and PCBM as electron acceptor as well as polyethylenedioxythiophene:polystyrenesulfonate (PEDOT:PSS) as highly conductive interfacial layer. The device structure was the following: ITO/PEDOT:PSS( 40nm)/active layer $(\sim 100 \mathrm{~nm}) / \mathrm{Al}(\sim 120 \mathrm{~nm})$. Indium tin oxide-coated glass with a surface resistance lower than $20 \Omega / \mathrm{sq}$ was used after sequential ultrasonic cleaning in acetone, isopropyl alcohol, and deionized water. After an additional UV-ozone cleaning step of the ITO, the PEDOT:PSS was spin-coated (60 second at $1200 \mathrm{rpm}$ and 120 seconds at $2000 \mathrm{rpm}$ at a constant $200 \mathrm{rpm} \mathrm{sec}$ acceleration) from an aqueous solution and dried for $30 \mathrm{~min}$ at $120{ }^{\circ} \mathrm{C}$ under vacuum before being transferred to the nitrogen-filled glovebox. The dichlorobenzene solutions were stirred at $70{ }^{\circ} \mathrm{C}$ for at least $24 \mathrm{~h}$ before spincoating. The solution had a total concentration of $40 \mathrm{mg} / \mathrm{mL}$ with a polymer/fullerene/compatibilizer weight fraction ratio similar to those used for AFM investigations. The active layer thickness (around $100 \mathrm{~nm}$ ) was measured using a Dektak Veeco profilometer. Finally, a $120 \mathrm{~nm}$ thick aluminum layer was thermally evaporated and used as cathode. A post-elaboration thermal annealing step of 15 minutes at $140^{\circ} \mathrm{C}$ has been performed systematically. The device active area was $9 \mathrm{~mm}^{2}$, while each sample included four independent diodes. Current versus voltage $(\mathrm{J}-\mathrm{V})$ characteristics were measured under darkness and under AM1.5 $\left(100 \mathrm{~mW} / \mathrm{cm}^{2}\right)$ illumination using an Oriel $150 \mathrm{~W}$ solar simulator.

\section{Results and discussion}

\subsection{Photovoltaic devices}

The device performances as a function of the active layer compositions are summarized in Table 2. On block copolymer free reference devices a short-circuit current $\left(\mathrm{J}_{\mathrm{sc}}\right)$ of 8.1 $\mathrm{mA} / \mathrm{cm}^{2}$, an open-circuit voltage $\left(\mathrm{V}_{\mathrm{oc}}\right)$ of $0.59 \mathrm{~V}$, a fill factor $(\mathrm{FF})$ of $50 \%$ and a power conversion efficiency (PCE) of $2.5 \%$ have been measured. Adding $2 \mathrm{wt} \%$ of compatibilizer into the blend increases significantly all the photovoltaic parameters and leads to a $3.2 \%$ power conversion efficiency. This surprising result shows that the presence of a compatibilizer, besides stabilizing the morphology, may also enhance the device performances for a given experimental procedure. The origin of this behavior may be due to changes in the morphology, that favor charge generation (leading to higher $\mathbf{J}_{\mathrm{sc}}$ ) and charge transport (higher FF). Although similar or even higher conversion efficiencies have been obtained with pure P3HT/PCBM blends in optimized devices[1,19], adding the compatibilizer may enlarge the choice of processing parameters that lead to optimal operation, making the device elaboration procedure more robust. For higher copolymer amounts however, the device performances decrease significantly. The origin of this drop in performances will be discussed further below.

To investigate the influence of the copolymer on the device stability, the PCE has been measured on devices as a function of annealing time at $140^{\circ} \mathrm{C}$. The copolymer weight fraction was either $0,2.5$ or $5 \mathrm{wt} \%$. The P3HT purchased at Aldrich was used for this study. As shown in Figure 1, the reference sample PCE starts to increase and decreases after 420 minutes 
annealing. This initial increase points out that the as-deposited morphology of the reference blends was still far from optimum. A prolonged annealing time was necessary to reach similar performances than the devices including a small fraction of compatibilizer. This behavior corroborates the positive impact of the compatibilizer on the blend morphology at short annealing times, as suggested above.

The device containing a $2.5 \mathrm{wt} \%$ copolymer fraction was stable up to 300 minutes, but its performances decreased rapidly for longer annealing times. This drop in efficiency occurs faster with higher copolymer contents. A similar evolution holds for both homopolymers. Indeed, the device performances summarized in table 2 (using Merck P3HT), show a loss in performances that increases with copolymer fractions above $4 \%$. To understand the origin of both, the initial device improvement and the premature unexpected device failure induced by the copolymer, we have further investigated the thin film morphology as a function of composition and annealing time.

\subsection{Thin film morphology}

The AFM phase images obtained on ternary blend thin films with copolymer fractions of 0 (reference blend), $2 \mathrm{wt} \%$ and $5 \mathrm{wt} \%$ after a short heat treatment $\left(15\right.$ minutes at $140^{\circ} \mathrm{C}$ ) are shown in Figure 2. The morphology of the copolymer free P3HT/PCBM sample appears to be composed of a dense network of lamellae structures. A similar morphology has been observed for P3HT/PCBM blends before and is believed to be due to P3HT lamellae separated by amorphous regions where most PCBM molecules are localized [20,21]. Adding the block copolymer to the blend leads to significant changes in the morphology. For the $2 \mathrm{wt} \%$ copolymer sample, lamellae-like structures are still observed but appear to be less densely packed. The 2D rather than $1 \mathrm{D}$ nature of these features is corroborated by their dominant parallel alignment (see Figure 2b, black circle). In the $5 \mathrm{wt} \%$ copolymer film, a more disordered network of elongated structures is seen. The recurrent crossing of these structures (indicated by arrows in Figure 2c) point out that the film is composed, at least in the near surface region, of 1D fibrils rather than of 2D lamellae.

The observed morphologies are consistent with the idea that the strong affinity between the copolymer rod block and the homopolymer drives the P3HT rod preferentially into the P3HT lamellae, while the fullerene-grafted coil-block tries to minimize its interaction with P3HT by being localized mostly in the PCBM rich regions. For the lowest copolymer fractions, we may expect that the P3HT lamellar structure can be preserved, as it is seen for the $2 \mathrm{wt} \%$ copolymer sample (Figure $2 \mathrm{~b}$ ). For higher copolymer fractions however, a coreshell 1D fibril composed of a P3HT core and surrounded by the fullerene-grafted coil block as well as free PCBM molecules, may become energetically favorable. We therefore tentatively attribute the 1D features seen in the $5 \mathrm{wt} \%$ copolymer sample (Figure 2c) to such core-shelltype fibrils.

Surprisingly, for the highest copolymer ratio, micrometer-sized objects can be observed all over the film. The latter are absent in the as-deposited as well as shortly annealed films of blends with lower copolymer content. Their irregular angular shapes suggest these objects to be crystalline. To investigate further the nature of these domains we performed spatially resolved secondary ion mass spectrometry [18]. Both, a reference and a blend with $10 \mathrm{wt} \%$ compatibilizer were analyzed by NanoSIMS50. The measurements were done on as-deposited as well as on annealed films. The distribution of P3HT, corresponding either to the homopolymer or the copolymer rod-block, could be visualized by following the sulfur (32S) isotope distribution, which is absent in PCBM. Additionally, as PCBM contains one oxygen atom and as the molar fraction of PCBM is seventy seven times higher than the copolymer fraction, the distribution of the $16 \mathrm{O}$ isotope can also be used to map PCBM. Note however, 
that the presence of oxygen impurities in the P3HT domains cannot be avoided and reduces the contrast.

The results of the NanoSIMS50 acquisition are shown in Figure 3. The variation of the grey scale color (black to white) is proportional to the intensity of the element detected. In the reference sample, a homogenous $32 \mathrm{~S}$ distribution was found on the as-deposited film (Figure $3(\mathrm{a} 1)$ as well as on the shortly annealed $\left(15\right.$ minutes at $\left.140^{\circ} \mathrm{C}\right)$ film Figure 3 (a2)). We can therefore conclude that the P3HT (and consequently PCBM) are homogenously distributed on a length scale larger than $50 \mathrm{~nm}$ (the spatial resolution of our equipment). In contrast, on the film that has been annealed for 3 hours, a 32S depletion is observed within a micrometersized region (Figure 3(a3)). This depletion necessarily goes along with an increase in PCBM content since all other major blend components include sulfur. The 160 map, shown in Figure 3(a4), confirms the high PCBM content within the sulfur poor region. We therefore may identify this region as a PCBM aggregate. Moreover, its irregular shape suggests the PCBM aggregate to be crystalline. Note that the PCBM aggregate appears to be linked to a second specific region visible in the $32 \mathrm{~S}$ image by a slightly brighter contour. The same region can also be seen in the 160 map (again due to a slightly brighter contour). This feature could correspond to border effect due to the morphologic of the crystalline. In this case, the secondary ions detected come from the border and from the surface don't have the same angular distribution, and so the same secondary intensity.

The behavior of the compatibilized blend is considerably different. A relatively large number of small PCBM aggregates can be seen already in the as-deposited film (Figure 3(b1)). After annealing, the size of the aggregates increases significantly while their density decreases simultaneously. These results indicate a local PCBM depletion and suggest that diffusion of PCBM molecules at high temperature allows the aggregates to grow by an Ostwald ripening process.

The SIMS results allow us to conclude that the microdomains seen by AFM in the 10 wt\% copolymer sample (Figure 2d) are composed of PCBM, in a presumably crystalline phase. Similar features have been seen by optical microscopy (not shown) in samples with lower content but after longer annealing times. In other words, the number of PCBM crystallites increases with the compatibilizer content for a given heat treatment. However, only for the highest copolymer fraction $(10 \mathrm{wt} \%)$ could the crystallites be seen in the asdeposited films.

Interestingly, for the compatibilized blend, no impurity or defect similar to those seen in the reference blend (Figure 3(a3)) could be detected in the proximity of the aggregates. We may thus conclude that nucleation of PCBM crystallites in the compatibilized films is not induced by the presence of impurities. Rather, since the number of aggregates scales roughly with the copolymer content, we believe that the copolymer itself, and more specifically the fullerene-grafted coil block, acts as nucleation center for PCBM crystallization.

From these morphology investigations we may conclude that the rapid drop in the photovoltaic performances, observed upon long term annealing, for the devices including the compatibilizer (Figure 1) is most likely due to the enhanced nucleation of PCBM micrometer crystals. Indeed, both, the depletion of PCBM in the neighboring regions and the macrodomains induced by the crystal growth, reduce considerably the D/A interface effective area and thereby lower the charge photogeneration rate as well as the overall conversion efficiency.

\section{Conclusion}


We have described the influence of P3HT- $b$-P(BA-stat- $\left.\mathrm{C}_{60} \mathrm{MS}\right)$ block copolymer used as compatibilizers in $\mathrm{P} 3 \mathrm{HT} / \mathrm{PCBM}$ blends. A strong correlation has been demonstrated between the morphology and the photovoltaic performances. In particular, a significant improvement in power conversion efficiency could be obtained by adding a small fraction of compatibilizer. Although a similar efficiency has been reported for pure P3HT/PCBM blends after optimization of the film deposition, our results point out that the introduction of compatibilizers may lead to an appropriate morphology even in, otherwise, non-optimized processing conditions.

Extended isothermal annealing of compatibilized blends was found to lead to rapid formation of PCBM aggregates and to cause preliminary device failure. This phenomenon increases with the block copolymer concentration and reveals that grafted fullerene behave as nucleation centre for the PCBM crystal growth. The use of a coil block that does have a strong affinity towards PCBM without being fullerene grafted (for instance poly(4vinylpyridine)), may be an interesting alternative [22, 23].

Acknowledgements: The authors thank the Region Alsace and the French Research Agency (ANR) for financial support and are grateful to Damien Vadillo for his contribution to the manuscript writing.

1. M. Reyes-Reyes, K. Kim, J. Dewald, R. Lopez-Sandoval, A. Avadhanula, S. Curran, D. L. Carroll, Org. Lett. 7, 5749 (2005)

2. D. Chirvase, J. Parisi, J. C. Hummelen, V Dyakonov, Nanotechnology 15, 1317 (2004)

3. V. Choong, Y. Park, Y. Gao, T. Wehrmeister, K. Mullen, B. R. Hsieh, C. W. Tang, Appl. Phys. Lett. 69,1492 (1996)

4. J. J. M. Halls, R. H. Friend, Synth. Met. 85, 1307 (1997)

5. J. J. M. Halls, K. Pichler, R. H. Friend, S. C. Moratti, A. B. Holmes, Appl. Phys. Lett. 68, 3120 (1996)

6. D. E. Markov, J. C. Hummelen, P. W. M. Blom, A. B. Sieval, Phys. Rev. B 72, 045217 (2005)

7. G. De Luca, E. Treossi, A. Liscio, J. M. Mativetsky, L. M. Scolaro, V. Palermo, P. J. Samor, Mater. Chem. 20, 2493 (2010)

8. S. S. Bavel, E. Sourty, G. With, J. Loos, Nanoletter 9, 507 (2009)

9. T. Salim, L. H. Wong, B. Bräuer, R. Kukreja, Y. L. Foo, Z. Bao, Y. M. J. Lam, J. Mater. Chem 21, 242 (2011)

10. R. Bechara, N. Leclerc, P. Lévêque, F. Richard, T. Heiser, and G. Hadziioannou, Appl. Phys. Lett. 93, 013306 (2008)

11. C. Yang, J. K. Lee, A. J. Heeger, F. J. Wudl, J. Mater. Chem. 19, 5416 (2009)

12. S. B. Darling, Energy Environ. Sci. 2009, 2, 1266.

13. K. Sivula, Z.T. Ball, N. Watanabe, J.M.J. Frechet, Adv. Mater. 18, 206 (2006)

14. J.U. Lee, J.W. Jung, T. Emrick, T.P. Russel, W.H. Jo, J. Mater. Chem. 20, 3287 (2010)

15. J.B. Kim, K. Allen, S.J. Oh, S. Lee, M.F. Toney, Y.S. Kim, C.R. Kagan, C. Nuckolls, Chem. Mater. 22, 5762 (2010) 
16. M. Jeffries-El, G. Sauvé, R. D. McCullough, Macromolecules 38, 10346 (2005)

17. F. Richard, C. Brochon, N. Leclerc, D. Eckhardt, T. Heiser, G. Hadziioannou, Macromol. Rapid Commun 29, 885 (2008)

18. J. N. Audinot, P. Lévêque, R. Bechara, N. Leclerc, J. Guillot, H. N. Migeon, G. Hadziioannou, T. Heiser, Surface and Interface Analysis 42, 1010 (2010)

19. A. J. Moulé and K. Meerholz, Adv. Funct. Mat. 19, 3028 (2009)

20. M. Reyes-Reyes, K. Kim, D. L. Caroll, Applied Physics Letters 87, 083506 (2005)

21. X. Yang, J. Loos, S.C. Veenstra, W.J.H Verhees, M.M. Wienk, J.M. Kroon, M.A.J. Michels, R.A.J. Janssen, Nano Lett. 5, 580 (2005)

22. N. Sary, F. Richard, C. Brochon, N. Leclerc, P. Lévêque, J. N. Audinot, S. Berson, T. Heiser, G. Hadziioannou, R. Mezzenga, Advanced Materials 6, 763 (2010)

23. A. Laiho, H. Ras, S. Valkama, J. Ruokolainen, R. Österbacka, O. Ikkala, Macromolecules 39, 7648 (2006)

\section{$\underline{\text { Schema caption: }}$}

Schema 1. P3HT- $b-\mathrm{P}\left(\mathrm{BA}-\right.$ stat- $\left._{60} \mathrm{MS}\right)$ rod-coil block copolymer.

\section{Figure caption:}

Figure 1. Normalized PCE as a function of annealing time at $140^{\circ} \mathrm{C}$ for devices with copolymer weight ratios of $0 \mathrm{wt} \%$ (triangles), $2.5 \mathrm{wt} \%$ (circles) and $5 \mathrm{wt} \%$ (squares), respectively.

Figure 2. AFM phase images on thin films after 15 minutes at $140^{\circ} \mathrm{C}$ as a function copolymer content: a) $\mathrm{P} 3 \mathrm{HT} / \mathrm{PCBM}$, b) $\mathrm{P} 3 \mathrm{HT} / \mathrm{PCBM} / 2 \mathrm{wt} \%$ copolymer, c) $\mathrm{P} 3 \mathrm{HT} / \mathrm{PCBM} / 5 \mathrm{wt} \%$ copolymer, d) AFM height image for P3HT/PCBM/10 wt $\%$ copolymer. The scan area is $1 \mu \mathrm{m}$ $\mathrm{x} 1 \mu \mathrm{m}$ for a), b) and c) while it is $20 \mu \mathrm{m} \times 20 \mu \mathrm{m}$ for d).

Figure 3. NanoSIMS50 images showing the ${ }^{32} \mathrm{~S}$ distribution in a) P3HT/PCBM and $b$ ) P3HT/PCBM/10 wt\% block copolymer bulk heterojunctions. The grey scale of the different images goes from black to white with increasing intensity. a1 and b1 correspond to as deposited films; $\mathrm{a} 2$ and b2 where measured after 15 minutes at $140^{\circ} \mathrm{C}$, and $\mathrm{a} 3$ and b3 after an additional 180 minutes at $140^{\circ} \mathrm{C}, \mathrm{a} 4$ and $\mathrm{b} 4$ are the ${ }^{16} \mathrm{O}$ distributions of the same samples than a3 and b3, respectively.

\section{Table caption :}

Table 1. Properties of the copolymer

Table 2. Evolution of the photovoltaic device performances, after 15 minutes at $140^{\circ} \mathrm{C}$, for increasing copolymer contents. 
Schema 1.

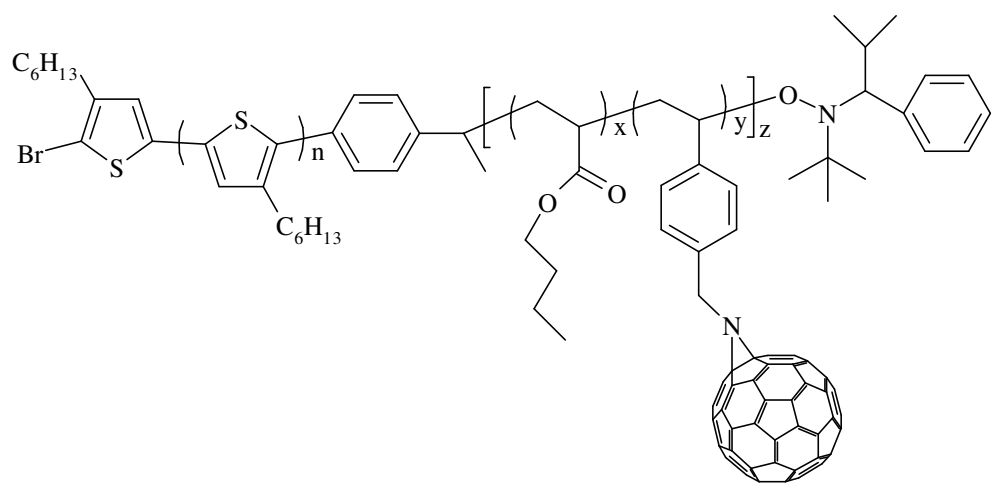

Figure 1.

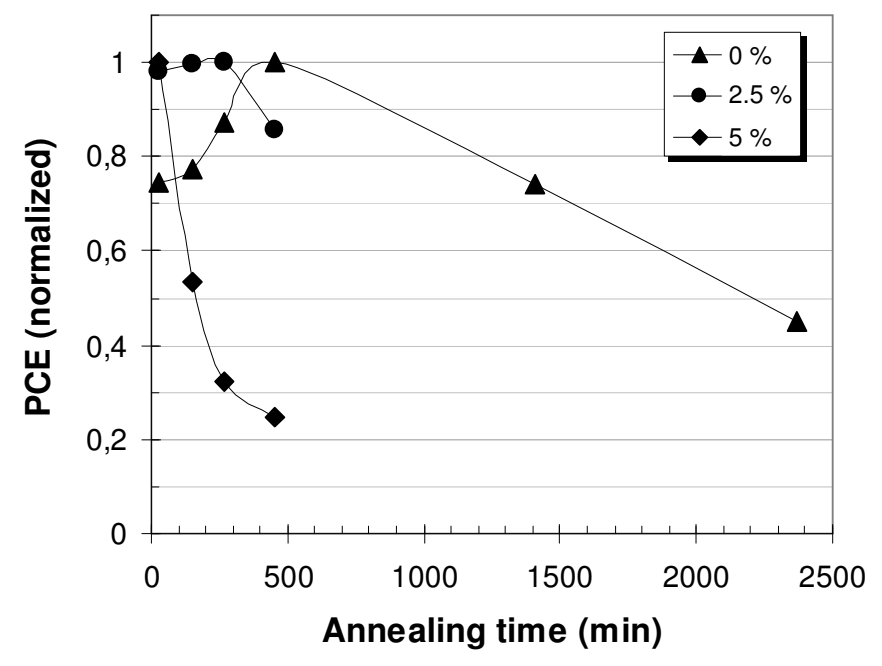

Figure 2.

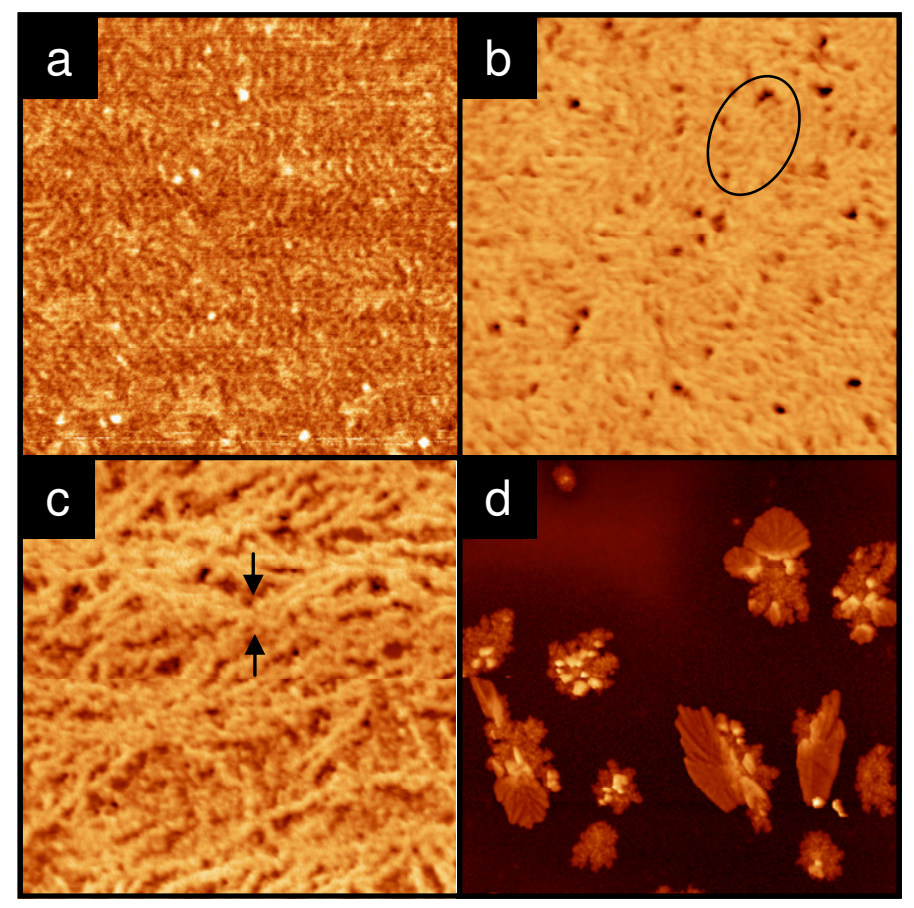


Figure 3.

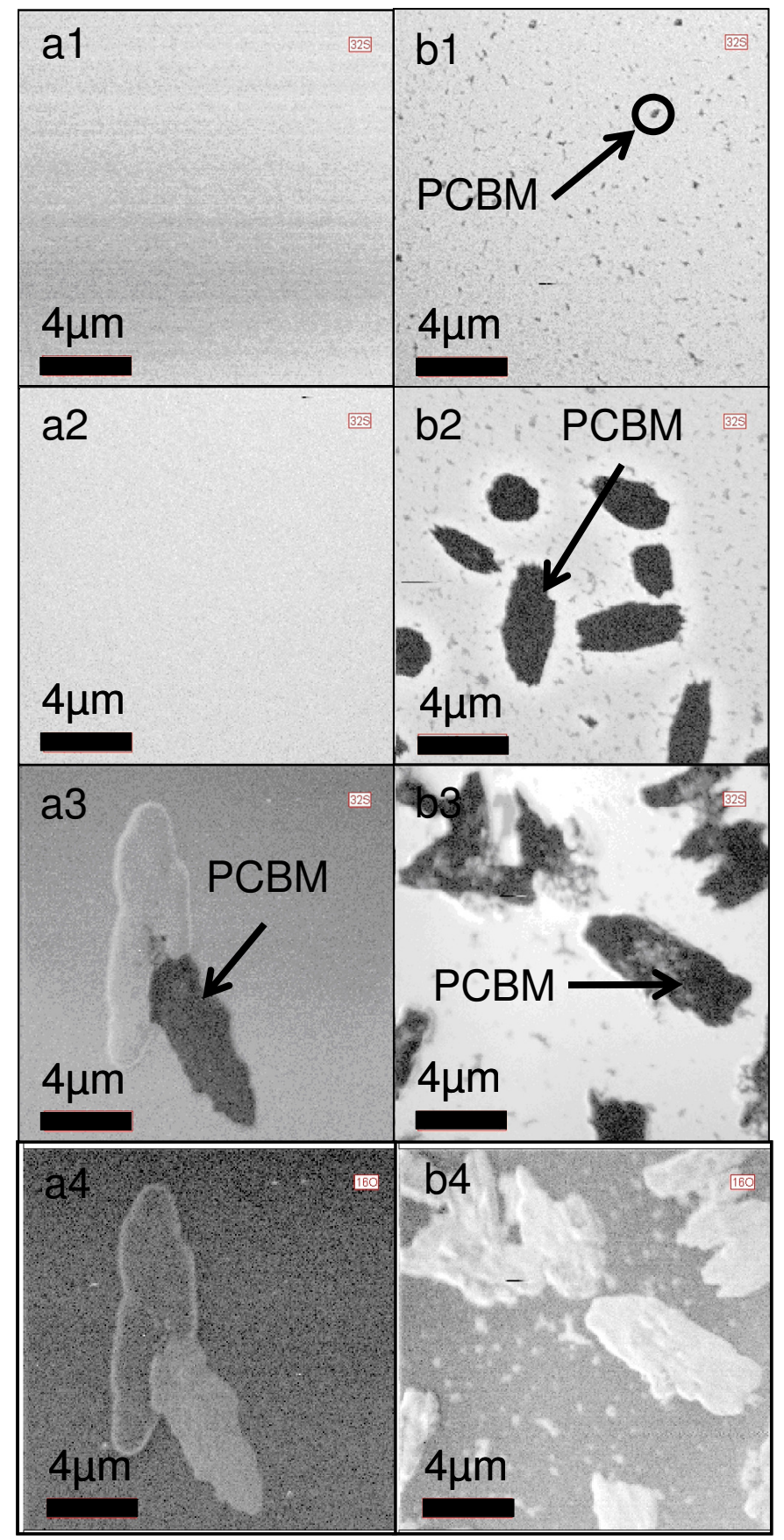


Table 1.

\begin{tabular}{|c|c|c|c|c|c|}
\hline $\begin{array}{c}\text { Copolymer Mn } \\
{[\mathrm{Kg} / \mathrm{mol}]}\end{array}$ & $\begin{array}{c}\text { Rod Mn } \\
{[\mathrm{Kg} / \mathrm{mol}]}\end{array}$ & $\begin{array}{c}\text { Rod rr } \\
{[\%]}\end{array}$ & $\begin{array}{c}\text { Coil Mn } \\
{[\mathrm{Kg} / \mathrm{mol}]}\end{array}$ & $\mathrm{C}_{60} /$ chain & $\begin{array}{c}\mathrm{C}_{60} \text { weight in copolymer } \\
{[\%]}\end{array}$ \\
\hline 14.0 & 2.0 & 93 & 9.4 & 6.3 & $28 \%$ \\
\hline
\end{tabular}

Table 2.

\begin{tabular}{|c|c|c|c|c|}
\hline $\begin{array}{c}\text { Copolymer fraction } \\
\text { [weight \%] }\end{array}$ & $\begin{array}{l}\text { Voc } \\
{[\mathrm{V}]}\end{array}$ & $\begin{array}{c}\text { Jsc } \\
{\left[\mathrm{mA} / \mathbf{c m}^{2}\right]}\end{array}$ & $\begin{array}{c}\text { FF } \\
{[\%]}\end{array}$ & $\begin{array}{l}\text { PCE } \\
{[\%]}\end{array}$ \\
\hline 0 & 0.59 & 8.1 & 50 & 2.5 \\
\hline 1 & 0.6 & 8.2 & 50 & 2.5 \\
\hline 2 & 0.62 & 9.4 & 55 & 3.2 \\
\hline 4 & 0.57 & 9.3 & 42 & 2.2 \\
\hline 5 & 0.57 & 9.2 & 39 & 2.0 \\
\hline 8 & 0.56 & 4.7 & 24 & 0.6 \\
\hline
\end{tabular}

